\title{
Ingenuity Pathway Analysis of Clozapine-Induced Obesity
}

\author{
Michael Myslobodsky \\ Howard University Graduate School, Washington, DC, and Clinical Brain Disorders Branch, NIMH/National Institutes of Health, Bethesda, \\ MD, USA
}

\section{Key Words \\ Weight regulation - Atypical neuroleptics . \\ Microvasculature - Tissue edema}

\section{Summary}

Background: Lipid accretion is one of the major side effects of clozapine pharmacotherapy of schizophrenia that made clozapine into an interesting obesity drug model. Method: Ingenuity Pathway Analysis (IPA) engine was used for core analysis and building the networks of weight regulation. Results: The examination of molecules that were selected into 'clozapine neighborhood' identified them as multifunctional signals that appear to orchestrate vascular and tissue functions plausibly implicated in adiposity side effect. Conclusions: It is hypothesized that clozapine unmasks the functional and morphological phenotype of microvascular deficit that facilitates shunting nutrients from utilization toward storage.

\section{Introduction}

A search for a credible model of human obesity draws attention to clozapine-induced weight gain. Clozapine remains the major drug for treating patients with refractory schizophrenia [1-8], and thus weight gain under clozapine, however disquieting medically, can be conceived of as an interesting human model of drug-induced obesity. The cognitive effects as well as specific molecular mechanisms possibly responsible for controlling phenotypic variability to clozapine are now largely well described $[9,10]$. By contrast, progress in understanding the pathogenesis of this side effect has been slow in particular, because molecular pathways to obesity are exceedingly multifarious. Likewise, a drawback of using clozapine as a model is that it belongs to the class of antipsychotics that act on a variety of receptor systems and pathways [for recent review see 11]. This capacity of clozapine to modulate in parallel several molecular targets earned it and the whole family of 'atypicals' a euphemistic acronym of 'MARTA' (for multi-acting receptor-targeted antipsychotics) [12]. Such 'shotgun' action is no longer considered a violation of classical models of psychopharmacology $[13,14]$, above all in treating polygenic disorders, such as affective disorders and schizophrenia. Yet, that does not simplify the analysis of its efficacy either, such that a narrative on the 'clozapine outreach' is no longer satisfying. In order to find some shortcuts in the expectedly complex datasets of both pharmacotherapy and obesity I took advantage of an analytical approach offered by the Ingenuity Pathways Analysis (IPA) [15]. By providing an automated, unbiased and statistically feasible identification of biologically relevant search procedures of multi-dimensional datasets, the IPA has proven to be a promising and time-efficient path of exploration of functions in the isolated metabolic, pharmacological and genetic drug-targeted networks [16].

\section{Material and Methods}

IPA represents a gateway to the manually built and periodically updated vast amount of biological information on all chemicals that have been modeled as drugs or clinical candidates. By entering a key word of interest into its search engine permits to explore all available information on its effects, molecular chemical, cellular, genetic, protein and mRNA interactions and create in a computationally rigorous and systematic manner custom molecular pathways (of 'network eligible molecules') supported by the current experimental literature evidence[ for review see 17]

A schematic in figure 1 summarized the steps made in the current experiment. It shows them as though conducted in the parallel legs and two stages. In practice, they are run sequentially and independently of each other. The first stage of the analysis began with the exploration of clozapine dataset, establishing criteria for the significances /p values for functions and pathways in IPA based on the size of pathway generated, and

\begin{tabular}{ll}
\hline KARGER & ๑ 2008 S. Karger GmbH, Freiburg \\
Fax +49761 45207 14 & Accessible online at: \\
$\begin{array}{l}\text { E-mail Information@Karger.de } \\
\text { www.karger.com }\end{array}$ & www.karger.com/ofa
\end{tabular}

\section{KARGER}

www.karger.com
Michael Myslobodsky, M.D., D.Sc. 


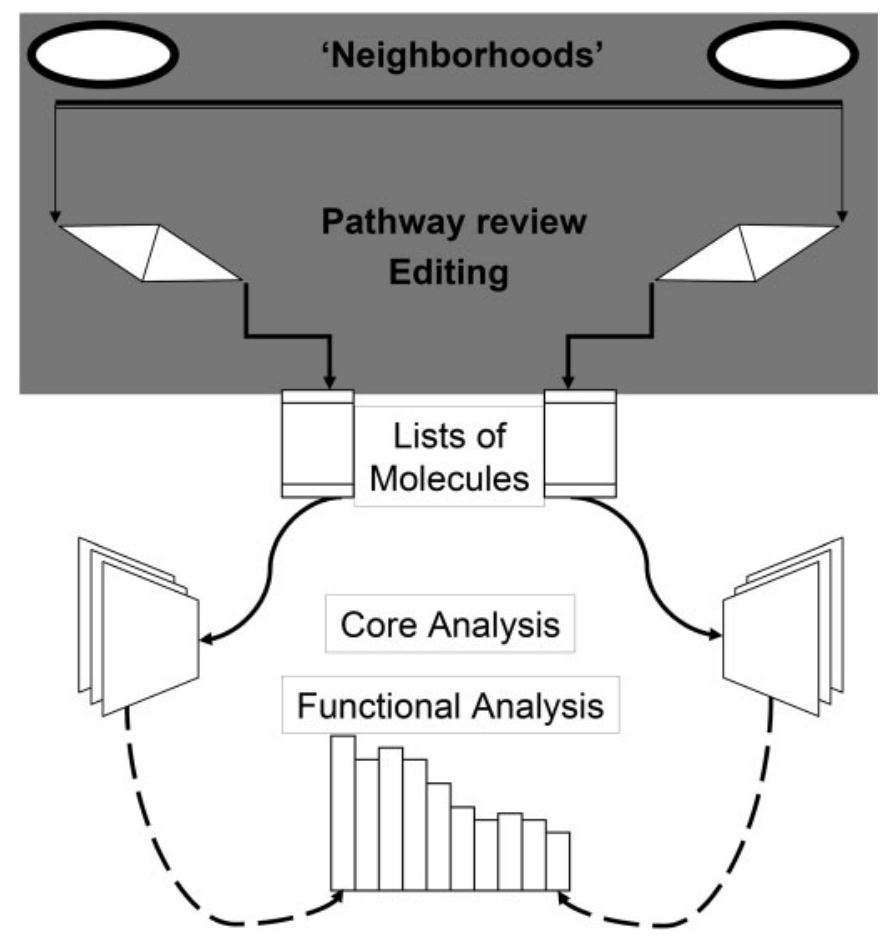

Fig. 1. Data flow for clozapine obesity analysis. The algorithm consists of two phases. Initial step derives data from 'neighborhood molecules' when clozapine neighborhood database was used for comparison with ingestion-control network. In the following stage, the list of molecules algorithm for both networks was submitted to the Ingenuity Pathways Analysis (IPA) [15]. At each stage, the networks could be edited at will.

condensing molecular sample. The second stage of the study was aided by the core analysis that represented the data for comparison, functional analysis and interpreting the results. Then, the logic of results prompted the query of molecules related to the network involved in ingestion control. The latter was then concluded with the core analysis to produce a subset of molecules and compare them with those relevant for clozapine effects.

The core analysis applies the principle of 'knowledge discovery' by using eligible molecules as 'seeds' for generating larger dataset and partitioning the document into subsets (networks) that could be dissimilar from each other. Nonetheless, the molecules within a single network have certain cohesion or are sufficiently related to each other. This 'high sensitivity-low selectivity' profile of the engine has heuristic advantages in interrogating the database, but its over-inclusiveness may need to be remedied by filtering or manual trimming (e.g. removing of chemical drugs, reactive groups, or chemical toxicants). Such 'coarser-graininess' offers time saving by allowing to ask questions without returning to the first step of data grouping.

The IPA makes the molecular bases of obesity a tractable problem. Its drawback is in being expectedly sensitive to the size of the retrieved molecular pool for pathway building. In part, this shortcoming is mitigated by the choice of drug. The diverse mechanisms underlying clozapine efficacy and its side effects have yielded voluminous data ('clozapine dataset') that is unmatched by similar repositories for other atypical neuroleptics. The significance of the association between the dataset and the pathway synthesized is estimated within the space of IPA as a ratio of the number of molecules from the dataset that met the expression value cutoff that map to the pathway divided by the total number of molecules that exist in the pathway displayed. Fisher's exact test is used to calculate a p value determining the probability that each biological function assigned to that network is due to chance alone. The statistically significant functional matches thus verified are given in table 2 (see below).

\section{Results}

\section{Clozapine Network ('Clozapine Neighborhood')}

The study was opened by the IPA-generated 'consensus topological structure' of clozapine global network (defined as 'clozapine neighborhood'; CN). The radius of the neighborhood is determined by IPA-annotated pharmacological data that are classified as biologically active. The latter illustrated all molecules relevant for its efficacy that could be grasped at a glance in graph. Consistent with these data, a standard $\mathrm{CN}$ synthesized by IPA was a clozapine-centric network with a few interconnected 'communities' different in degrees (e.g. represented by $\alpha$-adrenergic, dopaminergic, serotonergic, histaminergic and muscarinic acetylcholine receptors). The clozapine-centric format could easily reformatted by removing the drug, then pasting all molecules into a new window and prompting the software to execute connections of the nodes.

The reformatted network is shown in figure 2. Its layout emphasizes the cellular distribution of different kinds of nodes representing receptors, neurotransmitters, and enzymes. In order to facilitate the visualization of small clusters of nodes (hubs) dominating the network topology, the majority of indirect edges connecting the nodes are omitted. All the same, even after this reformatting, $\mathrm{CN}$ shown in figure 2 gives an adequate portrayal of clozapine 'polypharmacy' pattern [18]. The subcellular layout chosen for $\mathrm{CN}$ makes the graph more readable in that all hubs representing major classical neurotransmitters are separated on the right side of the graph (highlighted in black). According to IPA rules, all node connections are supported by at least one reference from the literature or from canonical information stored in the IPA Knowledge Base.

Examining figure 2, it is possible to notice that some molecules in the extracellular, cytoplasmic or the nuclear compartment of the subcellular layout of the network do not fit the neighborhood of classical neurotransmitters and their receptors. These were early growth response 1 (EGR), nuclear receptor subfamily 4 (NR4A1), C-fos proto-oncogene (FOS), $\mathrm{ABCB} 1 \mathrm{~B}$, prolactin (PRL), neurotensin (NTS), and tachykinin (substance P; TAC1). In order to increase their visibility, their nodes are enlarged and edges made bold. The common denominator of this small group is that their signals ultimately up-regulate different sets of genes that control tissue building, e.g. differentiation and hyperplasia (EGR1, NR4A1, ABCB 1B, PRL), survival of endothelial cells, formation of the neointima, and tubulation of endothelial cell (NR4A1), and damaged cell elimination through apoptosis (e.g. EGR1, NR4A1, ABCB1B, PRL). Likewise, FOS is a multifunctional gene that, too, is concerned with numerous aspects of tissue develop- 
Fig. 2. A subcellular layout of the reprogrammed clozapine neighborhood $(\mathrm{CN})$ generated using the Ingenuity Pathways Analysis. The IPA has an in-built facility representing diverse molecules and connections between them. Nodes' shapes represent the functional class of the molecule (node symbols based on IRA glossary are shown on the left). The relationships between the interacting nodes are indicated by continuous edges pointing from one node to another thereby signifying a direct influence (e.g., activation or inhibition) whereas interrupted

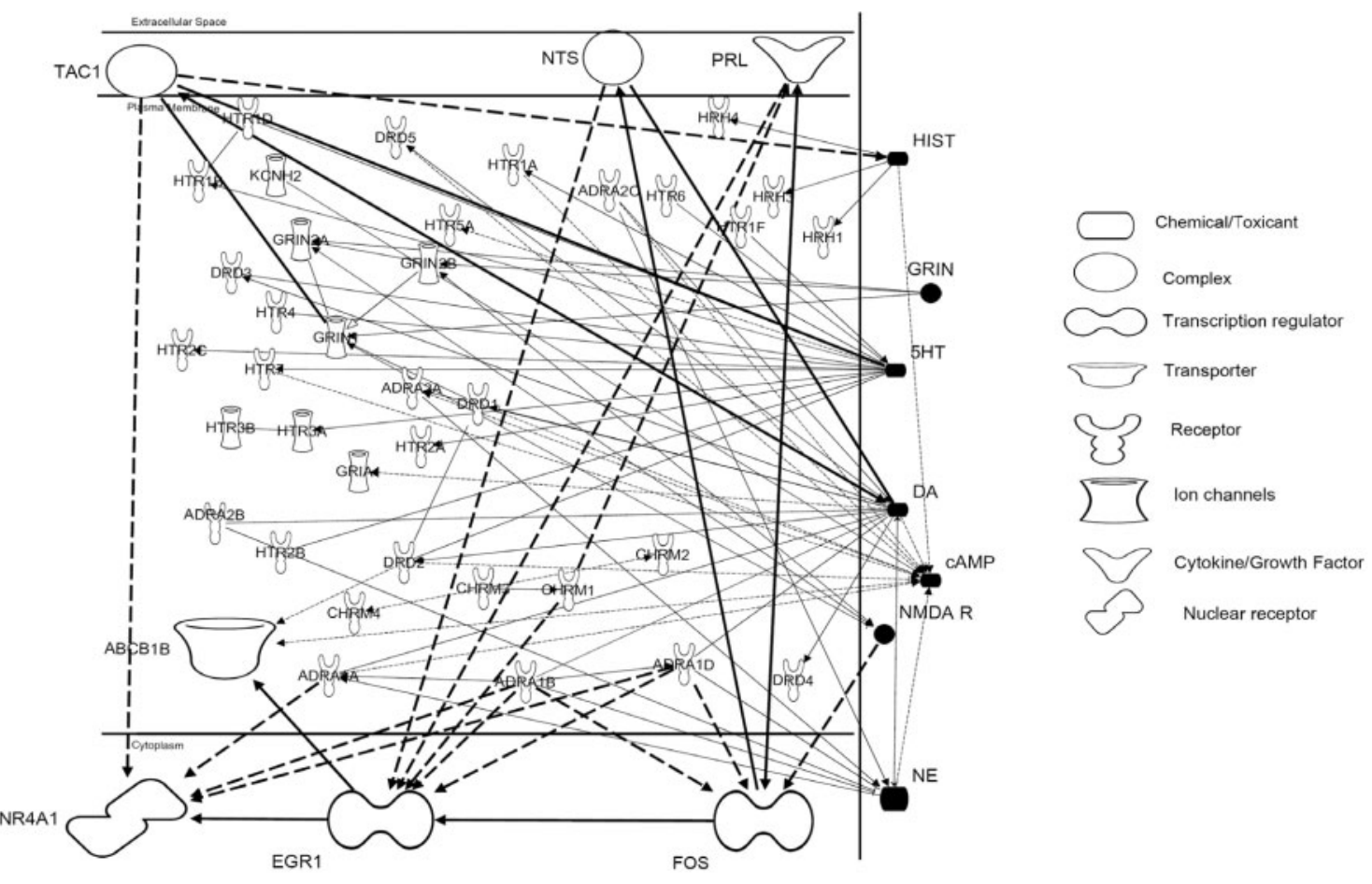
edges label the pres-

ence of indirect relations. All symbols describing the nature of the relationship between the nodes are omitted to reduce the clutter. For the same reason, not all receptors for the classical neurotransmitter systems are included and 'self-referential' edges that arise from the ability of a gene product to act upon itself are deleted. In order to increase visibility of ' $\mathrm{CN}$ outsiders' their nodes are enlarged and edges made bold. Note that classical neurotransmitter systems represent distinct separate hubs (highlighted in black on the right). For abbreviations see text, table 1 and figure 3.

ment and metabolic processes whereas TAC1 is known to control a host of events related to vascular contractility, permeability and angiogenesis, particularly activated by hypoxia-inducible factor-1 (HIF1). Their selection by the search engine was not readily explicable and initially, they were dubbed as $\mathrm{CN}$ 'outsiders'.

It was further surprising that a host of molecules that were expected to be involved in energy homeostasis as well as in peptidergic pathways emanating from the hypothalamus and active in other brain sites that create 'cognitive-appetitive modules' [19] were conspicuously absent from this consensus neighborhood. There is no denying that classical neurotransmitters play an obligatory role in energy homeostasis, if only by virtue of their responsibilities in food intake and reward mechanisms [20]. Yet none was crucial for gaining weight [21, 22]. Of the entire list of ingestion control peptide summarized in table 1, only NTS earned an initial entry to CN. However, NTS is a versatile and highly conserved molecule that would better fit into the group of ' $\mathrm{CN}$ outsiders'. It is implicated in cellular growth and motility, tissue morphology, proliferation, permeability, cardiovascular system development, and response to injury. Among its other roles is the regulation of neonatal cerebral hemodynamics compromised by hypoxia [23]. Hypoxia is an attractant for vessel sprouts and a potent inducer of EGR1 and EGF receptor (EGFR) transcription during development of cancers [24]. EGF and EGFR deter- mine cell fate in the embryonic brain [25], thereby suggesting that NTS may have been selected into $\mathrm{CN}$ for reasons other than its membership in table 1 .

\section{Clozapine Neighborhood Core Analysis}

In the next stage, the list of $\mathrm{CN}$ was submitted to the IPA core analysis when all original $\mathrm{CN}$ molecules were used as the 'seeds' or 'focus genes' in order to algorithmically generate networks based on their connectivity with IPA dataset. The analysis produced 137 molecules segregated into networks that were a significant departure from the pattern of the original 'seeds' in that their edges no longer converged into hubs representing the communities split along the classical neurotransmitter 'allegiances' (the graph is not shown). Network 1 and a non-overlapping with it network 2 were labeled by IPA as the site of organismal injury and abnormalities as well as psychological and neurological disorders. Network 3 represented neurological, dermatological and immunological conditions. Network 4 was a representation of processes that support cell-to-cell signaling as well as development and functions of the nervous system.

The heuristic benefit of scrutinizing these networks is that they expose molecules affected by clozapine (including classical neurotransmitters) that took part in an array of biological processes that were not viewed as primarily related to weight gain. Rather they contributed significantly under IPA signifi- 
Table 1. Partial list of factors contributing to appetite regulation

\begin{tabular}{|c|c|}
\hline Orexigenic factors & Anorexigenic factors \\
\hline Agouti-related protein (AGRP) & $\begin{array}{l}\text { corticotropin releasing hormone } \\
\quad(\mathrm{CRH})\end{array}$ \\
\hline $\begin{array}{l}\text { AMP-activated protein kinase } \\
\text { (AMPK) }\end{array}$ & $\begin{array}{l}\text { cocaine-amphetamine-regulated } \\
\text { transcript (CART) }\end{array}$ \\
\hline Dynorphin (PDYN) & cholecystokinin (CCK) \\
\hline Ghrelin (GHRL) & $\begin{array}{l}\text { gastrin-releasing peptide } \\
\text { (bombesin, GRP) }\end{array}$ \\
\hline Galanin (GAL) & glucagon-like peptide-1 (GLP1R) \\
\hline Endocannabinoids (CB1-R) & FAS inhibitors \\
\hline $\begin{array}{l}\text { Melanin-concentrating } \\
\text { hormone }(\mathrm{MCH})\end{array}$ & insulin (INS) \\
\hline Neuropeptide Y (NPY) & leptin (LEP) \\
\hline Orexin (hypocretin) (HCRT) & $\begin{array}{l}\text { melanocortin, melanocyte-stimulating } \\
\text { hormone }(\alpha-\mathrm{MSH}) \\
\text { neurotensin }(\mathrm{NTS}) \\
\text { oxytocin }(\mathrm{OXT}) \\
\text { urocortin (UCN) }\end{array}$ \\
\hline
\end{tabular}

cance criteria to cell growth and organogenesis, and, in particular, were recorded, as shown in table 2, in orchestrating developmental vascular patterning, vascular remodeling, vascular permeability and edema in the adult in different pathways and in dissimilar contexts. Although angiogenesis is reasonably well understood, there is little understanding of clozapine role in the adipogenesis beyond the fact that adiposity, above all of visceral type, is characterized by dyslipidemia and that both adipocytokines and dyslipidemia have a detrimental effect on microvascular function [26].

\section{Functions of Ingestion-Control List}

The 'double residency' of NTS in CN and table 1 suggests that the 'ingestion control peptide' may not be exclusively ingestive. By way of example, in mice, NPY induced angiogenesis that was inversely related to age (from 2 to 18 months of age) [27]. Scrutinizing table 1, one might observe that other molecules such as ADIPOQ, LEP, NPY, UCN, and OXT could be defined in a different context as 'non-classic' vascular agents [28]. Using path analysis it was possible to examine how many steps are required to go from one node to another along the shortest route from molecules representing any clozapine outsiders to the above molecules of the ingestioncontrol list shown elsewhere [19]. It appeared that the latter are connected by short paths to the maximal number of the host network directly or, at least, with one 'degree of separation' between any two nodes. This fully automatic pathway generation tool includes novel molecular routes and pathways that provide insights that could be explored in the future. An analysis of such an image takes several minutes for the search algorithm from a starting point. In practical terms, however, by permitting the network to grow by two separations adds to ingestive network over 20,499 edges that makes it unfit for visualization.

Path analysis proved that 'clozapine outsiders' are actually the legitimate insiders of the ingestion network. This prompted a parallel core analysis of the 'ingestion control network,' but for purposes of limiting the 'noise,' its list was trimmed such as to remove the classical neurotransmitters since the latter signals were already represented in $\mathrm{CN}$, and further information would have created a redundant set of networks. The molecules thus retrieved in the analysis were segregated into four networks. Network 1 represented behavior, nutritional disease, and psychological disorders. Network 2 loaded on behavior, cell morphology, and digestive system development and function. Network 3 represented organismal development, carbohydrate metabolism, and molecular transport. Network 4 represented cancer, cell cycle and cell-to-cell signaling. Core comparison analysis allowed visualizing their overlap with clozapine networks mentioned above. Their subsequent functional analysis showed a long inventory of roles executed by these molecules in different constellations (data not shown). In keeping with the principles of modularity, the same factors that are considered as dedicated to ingestion control might have been employed for 'nurturing' diverse tissues, initially prenatally, and then during the period of development when vasculogenesis and angiogenesis was a part of their tissue building roles. Perhaps, labeling these molecules as orexigenic and anorexigenic, as is a common practice that was also followed here in deference to tradition, is undeservedly restrictive. Based on this analysis, figure 3 portrays an update on a regular $\mathrm{CN}$ shown in figure 2 . In a new version, it is comprised of the map of classical neurotransmitters shown in an auto-layout format (fig. 3A) with an addition of a gamut of multifunctional molecules (fig. 3B) identified by IPA core and functional analyses, along with 'clozapine outsiders'.

Vascular development is a complex process involving tightly controlled expression of several genes and constant remodeling. Prenatally, these highly conserved genes are believed to regulate the development, functions and maintenance of various tissues, including vascular tissue. Postnatally, they possibly add to already established 'modules' other functions, such as control of ingestion and cognition [19]. They do not relinquish, however, their previous responsibilities. Table 2 exemplifies such repeated usage of LEP, TAC1, NTS or NPY in diverse contexts, such as hyperphagia, weight gain, cellular growth (hyperplasia) and proliferation as well as vasculogenesis and angiogenesis. Indeed, the term 'vasculogenesis' describes an active vascular production needed embryologically when blood vessels spring from differentiating endothelial cells or for sprouting of new blood vessels from the pre-existing ones. The same family of vascular endothelial growth factors is crucial for the development of the lymphatic vessels [29, 30]. In adulthood, however, the normal vasculature is dormant, with each endothelial cell dividing once every 10 years so that ac- 
Table 2. Samples of molecules identified in the course of the IPA core analysis and functional analysis of 'clozapine neighborhood' that appear to affect adipogenesis and orchestrate vascular and tissue functions

\begin{tabular}{|c|c|c|}
\hline Process Annotation & Significance* & Molecules** \\
\hline Differentiation of adipocytes & $1.47 \mathrm{E}-05$ & $A D I P O Q$, cyclic $A M P$, GH1, IGF1, INS1, LEP \\
\hline Mass of adipose tissue & $8.34 \mathrm{E}-11$ & $A G R P, \mathrm{CHRM} 3, C R H$, DRD2, GH1, HRH3, IGF1, LEP, $N P Y$ \\
\hline Weight gain & $5.88 \mathrm{E}-13$ & $A G R P, \mathrm{CRH}, G H 1$, HTR2C, IGF1, INS1, LEP, NPY, POMC, UCN \\
\hline Vasculogenesis & $1.42 \mathrm{E}-05$ & $\begin{array}{l}\text { 5-hydroxytryptamine, ADRA1B, ADRA2B, dopamine, DRD2, GH1, } \\
I G F 1, L E P, P R L \text {, SST, TAC1 }\end{array}$ \\
\hline Angiogenesis & $1.65 \mathrm{E}-05$ & $\begin{array}{l}\text { ADRA1B, ADRA2B, dopamine, DRD2, GH1, IGF1, LEP, PRL, SST, } \\
T A C 1\end{array}$ \\
\hline Quantity of cells & $1.24 \mathrm{E}-06$ & $\begin{array}{l}\text { 5-hydroxytryptamine, CRH, dopamine, DRD1, DRD2, EGR1, FOS, GH1, } \\
\text { histamine, HTR2B, IGF1, INS1, LEP, norepinephrine, NPY, NR4A1, } \\
\text { POMC, PRL, SST, TRH }\end{array}$ \\
\hline Growth of cells & $1.60 \mathrm{E}-03$ & $\begin{array}{l}\text { 5-hydroxytryptamine, ADIPOQ, ADRA1A, ADRA1B, cyclic AMP, } \\
\text { dopamine, EGR1, FOS, GH1, GRP, histamine, IGF, INS1, LEP, } \\
\text { norepinephrine, NTS, POMC, PRKAR2B, PRL, SST, TRH }\end{array}$ \\
\hline Proliferation of cells & $1.35 \mathrm{E}-13$ & $\begin{array}{l}\text { ADIPOQ, ADRA1A, ADRA1B, ADRA1D, ADRA2A, CHRM1, cyclic } \\
\text { AMP, CHRM3, CHRM4, CRH, GH1, HRH1, HTR2A, HTR2B, NPY, } \\
\text { 5-hydroxytryptamine, dopamine, DRD2, DRD3, EGR1, FOS, GRIA1, } \\
\text { GRP, histamine, IGF1, INS1, LEP, HTR1A, HTR2, norepinephrine, } \\
\text { NR4A1, OXT, OXTR, PRKAR2B, POMC, PRL, SST, TAC1, TRH, UCN }\end{array}$ \\
\hline Angioedema & $1.88 \mathrm{E}-12$ & $\begin{array}{l}\text { ADRA1A, ADRA1B, ADRA1D, ADRA2A, ADRA2B, ADRA2C, } \\
\text { CHRM1, CHRM2, CHRM3, CHRM4, HRH1, HTR2A }\end{array}$ \\
\hline Edema & $2.55 \mathrm{E}-16$ & $\begin{array}{l}\text { ADRA1A, ADRA1B, ADRA1D, ADRA2A, ADRA2B, ADRA2C, } \\
\text { CHRM1, CHRM2, CHRM3, CHRM4, histamine, HRH1, HTR2A, TAC1 }\end{array}$ \\
\hline Permeability of vasculature & 4.99E-08 & $\mathrm{CRH}$, histamine, NTS, TAC1, UCN \\
\hline Systolic pressure & $2.29 \mathrm{E}-15$ & $\begin{array}{l}\text { 5-hydroxytryptamine, } A D I P O Q \text {, ADRA1B, ADRA1D, ADRA2A, } A S I P \text {, } \\
\text { DRD2, IGF1, INS1, } L E P, O X T R \text {, TRH }\end{array}$ \\
\hline Hyperphagia & $2.81 \mathrm{E}-10$ & AGRP, ASIP, IGF1, INS1, LEP, NPY, POMC \\
\hline
\end{tabular}

*Note: The IPA computes p values by comparing the number of molecules of interest relative to the total number of occurrences of these molecules in all functional/pathway annotations stored in the Ingenuity Pathways knowledge base (Fisher's exact test with $\mathrm{p}$ value adjusted using the Benjamini-Hochberg multiple testing correction). This test is a standardized choice in the IPA estimate of statistically significant findings. Only a partial list of functions is shown.

**Italicized molecules contribute to an increment of annotated processes. tive neovascularization (termed 'angiogenesis') is limited. It is recruited on special occasions such as wound healing, endometrial proliferation, or other processes related to pregnancy. The formation of new blood vessels is a hazardous event for it is associated with invasion of metastasis and all solid tumors. Microvascular formation is also needed for the development of adipose tissue $[31,32]$.

\section{Discussion}

\section{Clozapine Obesity as Vascular Pathology}

The central question is how clozapine could contribute to vascular abnormality. A number of pathways might be entertained. Clozapine is a potent releaser of OXT, as opposed to haloperidol that appears to be without effect [33]. OXT would conceivably contribute to adiposity if assumed that clozapine inhibited its activity, as was not found to be the case. On the other hand, OXT could play a significant role in angiogenesis via the phosphatidylinositol-3 kinase (PI3K)/AKT pathway that has been implicated in postnatal neovascularization [34]. Human umbilical vein endothelial cells (HUVECs) respond to OXT with an increased proliferation, suggesting a possible role for the hormone in the regulation of angiogenesis [35]. Likewise, NPY that activates OXT is a potent angiogenesis promoter in its own right, enhancing adhesion, migration, proliferation, and tubulation in vitro and angiogenesis in vivo. Another vascular modulator is LEP, which levels increase following atypical medication [36-38] even though hyperleptinemia might be seen during treatment with conventional antipsychotics, albeit in the latter case, mostly in men [39, 40]. Leptin is an intriguing agent that is known to enhance the expression of VEGF but also combines both a proliferative and strong angiostatic signals that counters the potentially lethal 
Fig. 3. Classical neurotransmitters of clozapine neighborhood in $\mathbf{A}$ auto-layout format and B a gamut of multifunctional molecules identified by IPA core and functional analyses (see table 2). Both graphs are connected via a clozapine bridging hub to emphasize that they are related to the same 'neighborhood'. Therefore, clozapine 'outsiders' were transferred to the B-section of the web. As in figure 2 , some ties are not represented in the graph, and all 'self-referential' edges, as well as the labels that describe the nature of the relationship between the nodes were omitted to reduce the clutter. Clozapine hub, as well as the size of nodes is overemphasized for visual clarity (their symbols are shown in figure 2). They do not communicate differences of functional hierarchy.

ADRA1A-1D, ADRA2A, ADRA2B, ADRA2C = Adrenergic receptor $\alpha$ 1a-1d; $\alpha$ 2a, 2b, 2c; AVP (AVPR1A, AVPR1B, AVPR2) = arginine vasopressin (and its receptors); cAMP = cyclic AMP; $\mathrm{CCK}=$ cholecystokinin receptor; $\mathrm{CHRM1-M4}=$ muscarinic receptor, $\mathrm{M}_{1}-\mathrm{M}_{4} ; \mathrm{CRH}=$ corticotropin releasing hormone; DRD1-D5 = dopamine $\mathrm{D}_{1}-\mathrm{D}_{5}$ receptor; EGR1 = early growth response 1 ; FOS $=$ viral oncogene homolog; GABA $=\gamma$-aminobutyric acid; GH = growth hormone; GRIA1 = glutamate receptor, AMPA 1; GRIN = glutamate receptor, NMDA ; HIF1 = hypoxia-inducible factor 1; HRH1-4 = histamine receptor $\mathrm{H}_{1}-\mathrm{H}_{4}$; HTR4-7 = 5-hydroxytryptamine receptors 4-7; HTR1A, 1B, 1D, 1F, 2A, 2B, 2C, 3A, 3B, 5A = 5-hydroxytryptamine receptors $1 \mathrm{~A}$ through $5 \mathrm{~A} ; \mathrm{KCNH} 2=$ potassium voltage-gated channel; $\mathrm{NE}=$ norepinephrine; $\mathrm{NR} 4 \mathrm{~A} 1$ = nuclear receptor subfamily 4 ;

NTS = neurotensin; $\mathrm{POMC}=$ pro-opiomelanocortin PRKACB, PRKAR2A, PRKAR2B = protein kinase PRL = prolactin; SST = somatostatin; TAC1 = tachykinin; substance $\mathrm{P}$; TRH = thyrotropin; VIP = vasoactive intestinal peptide (see also abbreviations in the text and table 1 ). leaking actions of VEGF [41]. Another ingestion control factor is UCN that is a potent inhibitor of feeding behavior. It is released together with corticotropin releasing hormone $(\mathrm{CRH})$ in the brain under stress and is one of the most effective triggers of skin vascular permeability in rat [42]. VEGF can stimulate formation of a variety of corridors through the endothelial cell, including transcellular gaps, vesiculovacuolar organelle formation, and fenestrations that collectively provide an essential gate, letting hormones and small molecules to escape into the tissue.

The adipogenic effect of clozapine is believed to be an iatrogenic phenomenon on par with tardive dyskinesia of classical neuroleptics. This view gets traction because it is hardly challenged. However, men and women with schizophrenia have somewhat higher mean BMI than do non-schizophrenic individuals at the outset of disease [43]. Therefore, it might not be surprising that weight gain afflicts up to $50 \%$ of patients on long-term administration of typical and atypical antipsychotic drugs [44]. What is the nature of this hypothetical 'intrinsic capacity' to gain weight? The answer I favor is motivated by the largely neglected findings and conceptualizations that schizophrenia psychoses are the result of damage to the microvascular system in the brain. Hanson and Gottesman [45] postulat- ed recently the presence of the early abnormalities of microvascular development (due to traumatic, infectious or hypoxic insults) that create a state of diathesis that could convert the vulnerability to an illness with advancing years. An oftmentioned marker of vascular pathology is a high visibility of the nailfold capillary beds. The latter was recorded in $70 \%$ of patients with familial schizophrenia and $19 \%$ of patients with sporadic schizophrenia [46]. Curiously, those rated as having greater nailfold capillary visibility had more negative (treatment refractory) symptoms while there was no relationship to positive symptoms. As clozapine is particularly efficacious for negative symptoms, the former group of patients is more likely to be treated with clozapine than the latter.

While confirmation of a particular vascular aberration in schizophrenia awaits description of the knockout phenotypes, patients on antipsychotic medications are occasionally manifest angio-edematous cutaneous reactions [47]. Admittedly, there are only a handful of examples where clozapine has been shown to be primarily responsible for edemas [48-50], and it is difficult to tell whether the patients had some premorbid abnormalities of lymphatic vessels or experienced them subjectively when treated. There is no information on their sensations suggestive of edema, but it is fair to say that 
such complaints if reported would have a chance to being attributed to 'psychosomatic dermatology' or categorized as 'delusions of parasitosis' [51]. A special attention to such cases is warranted since lymphatic traffic is a significant player in mopping up transcapillary albumin and water that constantly escapes to the tissue, and return them to blood flow. Consequently, a deficient uptake of interstitial fluid could lead to edema, experienced subjectively or not.

The same route may be used by diverse nutrients that escape bloodstream unchecked. Harvey et al. [52] recently reproduced experimentally lymphatic vasculature dysfunction as a cause of adult-onset obesity by showing that functional inactivation of a single allele of the homeobox gene Proxl led to lymphedema with consequent hypertrophy or hyperplasia of adipocytes. At 6- to 12-month of age, these mice were noticeably heavier than their wild-type littermates. The discovery of the role of Proxl inaugurated the new field in obesity research. An indication of the importance of this pathway was illustrated by showing that most severely dilated lymphatic vessels in Prox1+/- mice were in the intestinal lymphatic network and mesentery that were a likely source of visceral obesity. Pups that died soon after birth had features of lymphatic dysfunction: leakage of chyle from mesenteric lymphatic vessels and accumulation of lipids in the intestinal wall.

The Harvey's model along with the findings that tissue alteration and angiogenesis could be also important obesity factors $[32,53]$ permit to conceive of the role of clozapine in the new light as a trigger of vascular-related obesity. Could rather mechanistically, clozapine facilitate trafficking nutrients from utilization toward storage? Could it simply act to unmask a low-level (subclinical) edema of the subcutaneous and omental tissues? On the basis of what we know, these possibilities cannot be ruled out. At the very least, clozapine cannot be conceived of promoting obesity by appetite enhancement alone. Table 2 lists a number of molecules that could contribute to hyperphagia. A recent study by Kim et al. [54] highlights the potential role of hypothalamic AMP-protein kinase (AMPK) in this regard. However, AMPK is acting in diverse pathways and is an important participant of angiogenesis control $[55,56]$. Its AMPK $\alpha 1$ subunit is a modulator of angiogenesis and vascular tone independent of NO and the presence of endothelium [57] that could considerably confound the result as maintained in the present study. It is plausible that hyperleptinemia caused by clozapine would potently stimulate AMPK, both on the level of muscular tissue and via the hypothalamic-sympathetic nervous system axis, as was shown by Minokoshi et al. [58] Acting in tandem, AMPK and LEP molecules could conceivably augment angiogenesis. Therefore, not ruling out the role of clozapine in hyperphagia, the possibility favored here is that the drug targets endothelial cells, even if subtly, that contributes to the formation of new leaky blood vessels and lymphatic vessels (lymphangiogenesis) [59-62].

\section{Clozapine Obesity and Prenatal Stressors}

An important problem for the present hypothesis is that the microvascular hypothesis of schizophrenia [45] does not provide a general principle for why neurovascular disorder might lead to obesity or metabolic syndrome. Again, a single explanation is hardly on hand since schizophrenia is conceived of as a disorder created by (multiple) genetic and/or pre- and perinatal factors [63]. The roles of genes in aberrant performance of lymphatic endothelial cell markers seems to be well supported [e.g. 52, 64] even if their number and roles associated with neurodevelopmental pathology have yet to be elucidated. Owing to space restrictions, only a brief mention should be made that numerous studies in both humans and experimental animals have established the role of intrauterine or perinatal environment as stressors that in their own right may lead to disease in adult life, including adiposity and metabolic syndrome $[65,66]$.

Prenatally stressed females have elevated basal plasma corticosterone levels in adulthood as compared to non-stressed controls. Vascular reactivity to NPY and electrical field stimulation in mesenteric arteries is known to be significantly increased in prenatally stressed animals [67]. Another example is provided by Gao et al. [68] who while studying male offspring of nicotine-exposed dams obtained increased postnatal body weight and fat pad weight, an increased amount of perivascular fat as well as an alteration in vascular relaxation response following neonatal exposure to maternal nicotine. Strikingly, the whole gamut of abnormalities has become clear only in adulthood, at 26 weeks of age. The nature of this syndrome is uncertain, but one of its components could be a greater permeability of vessels leading to tissue edema and its evolution into fat tissue.

For example, EGF when administered to neonatal rats (every other day until postnatal day 10) seemed rather harmless since its effects were not particularly obvious from the type of evaluation employed. The animals gained weight normally and showed no histological or gross brain abnormalities. In adulthood, however, (days 24 and 52) the rats began to display various behavioral abnormalities in social interaction and deficits in prepulse inhibition of acoustic startle as compared to control (cytochrome c-treated) littermates. Their motor activity, which likewise was seemingly normal in earlier developmental stages, became impaired in adulthood [69]. These behavioral alterations reminiscent - as the authors believe - of some animal models of schizophrenia were attenuated by chronic treatment with clozapine. It remains uncertain, however, how the exogenous supply of EGF used to alter endogenous EGFR signaling in the brain changed somatic microvasculature.

\section{Adipocytes: Hyperplasia or Hypertrophy?}

Obesity is comprised of hyperplasia and/or hypertrophy of adipocytes that differ in degree in diverse sites of the body, or a combination of both $[53,70]$. Table 2 identifies some mole- 
cules that might be involved in hyperplasia and hypertrophy of adipocytes. This anatomical variance has yet to be taken into account in discussing clozapine obesity. Metabolically, these two processes are dissimilar [71]. Adipose cell differentiation in vitro, proceeds from immature cells (adipoblast) and preadipocytes to mature adipose cells (adipocytes). Preadipocytes treated with clozapine showed a significantly higher percentage of conversion of adipose tissue precursor cells to mature adipocytes [72]. Hypertrophy of adipocytes occurs during the initial stages of development of obesity. However, the capacity to hypertrophy is not boundless, and once adipocytes reached a critical size neo-adipocyte differentiation takes place under the influence of growth factors secreted by the hypertrophied cells. The ratio between the two types of cells matters for the fate of type 2 diabetes since adipocyte size is an important determinant of the expression of pro- vs. antiinflammatory factors. Presumably, smaller young adipocytes have significant health advantage for they are thought to be more effective in glucose disposal than bigger cells [73, 74] and act as 'metabolic buffers' by avidly absorbing fatty acids in the postprandial period [75]. Larger adipocytes are generally found to be less sensitive to insulin [76], and the presence of larger adipocytes in the abdominal depot is a marker of risk for developing type 2 diabetes. A shift toward more harmful predominance of pro-inflammatory adipokines was obtained with increasing adipocyte size [77].

Danforth [78] maintained that that type 2 diabetes is the result of the inability of the adipose organ to expand to accommodate excess calories. Another gross topography factor he mentioned as determining the vulnerability to metabolic syndrome (albeit also related to adipocytes morphology) is the visceral pattern of fat deposits. More recently, a direct association between (visceral) adiposity and functional or structural characteristics of the capillary network was reported [26]. Thakore et al. [79] demonstrated that visceral adiposity is relevant for schizophrenia. Using CT scanning for adiposity assessment in a cross-sectional study in drug-naive and drug-free schizophrenia, they reported that patients had over three times more intra-abdominal fat. Previous neuroleptic exposure did not appear to influence this result. This finding reminds that only a third of schizophrenic patients treated with clozapine for 5 years developed diabetes [4].

Central adipocytes more actively release the 'secretome' of the adipocytes, of which many have a pro-inflammatory function, presumably leading to the development of insulin resistance, hypertension, and cardiovascular morbidity [71]. Therefore, central obesity is more closely associated with insulin resistance, type 2 diabetes, and cardiovascular disease than subcutaneous (peripheral) obesity. A recently discovered visceral fat depot-specific secretory protein, suitably named omentin, may be a candidate gene for type 2 diabetes susceptibility in humans [80]. It was expressed in stromal vascular cells, but barely detectable in subcutaneous fat depots in humans. The role of clozapine in either of these factors has yet to be ex- plored. We must await the results of more extensive trials where the topography and the nature of adiposity (hyperplasia vs. hypertrophy) are taken into account.

\section{Conclusion and Therapeutic Perspectives}

The study suggested that clozapine-induced weight gain and metabolic syndrome could be associated with the inherently fragile and leaky microvascular system. That might conceivably add to the toolbox of obesity research in general. Hopefully, details from history, premorbid adiposity and some simple laboratory examinations based on Hanson and Gottesman [45] could narrow diagnostic possibilities in the future. Given that impaired endothelium is a vulnerable portal through which many plasma molecules infiltrate the tissue and deposit nutrients bypassing the redundant web of biochemical sensors, clozapine weight gain may not follow the simplistic 'calorie incalorie out' logic, whereas weight loss may not follow lifestyle changes. This is in keeping with Feinman's and Fine's [81] objection to the dictum 'a calorie is a calorie' even if for reasons other than its violation of the second law of thermodynamics. In a reciprocal functional overlap, circulating growth factors generated by developing tissues and capillaries may affect both blood vessel and nervous system, ultimately influencing behavior. It makes drugs with a weight-reducing effect an eagerly awaited solution.

The current anti-obesity drugs are limited to sibutramine, orlistat and rimonabant. They have demonstrated some efficacy, but their side effects are disappointing and certainly limit their use in schizophrenia. Likewise, the recently tested D1/D5 antagonist ecopipam (SCH 39166), appear to have some efficacy but was not free from side effects [82]. The challenge of designing an anti-obesity drug with a selective effect on energy and glucose homeostasis is complicated by the fact that the majority of neuropeptides, although acting in ingestion control, are multifunctional molecules also involved in executing numerous psychological functions such as sensory processing, memory, arousal, mood and emotions, time coordination, anxiety, aggression, learning, and locomotion [19]. Consequently, antiangiogenic agents evoke significant interest as a novel 'targeted therapy' modality in obesity [31]. Can antiangiogenic agents aim at clozapine obesity, as well? Opting to err on the side of caution, one might join Lijnen [32] by abstaining from this choice. Adipogenesis is a complex and multifactorial process that is unlikely to cause slimming without associated untoward effects. Admittedly, not all members of the angio/histopoietic network act synergistically. Antiangiogenic agents, including anti-VEGF therapies (e.g. bevacizumab), would lead to rarefaction and arterial hypertension. That could only aggravate obesity. Deficient vascular endothelial growth factor goes hand in glove with reduced microvascular density and hypertension [83] and could contribute to a reduction in lymph return by increasing peripheral vascular resis- 
tance and an increase in capillary pressure, shear and fragility of the vessels [29]. Intravascular pressure is suspected to induce some active endothelial processes causing openings in the wall of microvessels [84]. Clozapine itself causes elevated systolic and diastolic blood pressure soon after initiation of therapy, apparently anticipating weight gain [85]. The hope is that the potential benefits of targeting angiogenesis in the treatment of obesity would be more relevant as many more vascular antiangiogenic agents are identified in the coming years.

\section{Competing Interests}

The author declares to have no competing interests.

\section{Acknowledgements}

Discussions and reading by T. Goldberg, L. Ingraham and D. Weinberger as well as the helpful comments of the two anonymous reviewers are gratefully acknowledged. K.Qaadi (Ingenuity Systems) and D. Joubert (NIH) were supportive with Ingenuity Pathway Analysis.

\section{References}

1 Kane J, Honigfeld G, Singer J, Meltzer H: Clozapine for the treatment-resistant schizophrenic: a doubleblind comparison with chlorpromazine. Arch Gen Psychiatry 1988;45:789-96.

2 Pickar D, Owen RR, Litman RE, Konicki E, Gutierrez R, Rapaport MH: Clinical and biologic response to clozapine in patients with schizophrenia. Crossover comparison with fluphenazine. Arch Gen Psychiatry 1992;49:345-53.

3 Leadbetter R, Shutty M, Pavalonis D, Vieweg V, Higgins P, Downs M: Clozapine-induced weight gain: prevalence and clinical relevance. Am J Psychiatry 1992;149:68-72.

$\checkmark 4$ Henderson DC, Cagliero E, Gray C, et al: Clozapine, diabetes mellitus, weight gain, and lipid abnormalities: a five-year naturalistic study. Am J Psychiatry 2000;157:975-81.

5 Lieberman JA, Stroup TS, McEvoy JP, et al: Effectiveness of antipsychotic drugs in patients with chronic schizophrenia. N Engl J Med 2005;353: 1209-23.

6 McEvoy JP, Lieberman JA, Stroup TS, et al: Effectiveness of clozapine versus olanzapine, quetiapine, and risperidone in patients with chronic schizophrenia who did not respond to prior atypical antipsychotic treatment. Am J Psychiatry 2006;163: 600-10.

7 Hagg S, Lindblom Y, Mjorndal T, Adolfsson R: High prevalence of the metabolic syndrome among a Swedish cohort of patients with schizophrenia. Int Clin Psychopharmacol 2006;21:93-8.

8 Olfson M, Marcus SC, Corey-Lisle P, Tuomari AV, Hines P, L'Italien GJ: Hyperlipidemia following treatment with antipsychotic medications. Am J Psychiatry 2006;163:1821-5.

9 Goldberg TE, Weinberger DR: The effects of clozapine on neurocognition: an overview. J Clin Psychiatry 1994;55(suppl B):88-90.

10 Goldberg TE, Weinberger DR: Effects of neuroleptic medications on the cognition of patients with schizophrenia: a review of recent studies. J Clin Psychiatry 1996;57(suppl 9):62-5.

11 Nasrallah HA: Atypical antipsychotic-induced metabolic side effects: insights from receptor-binding profiles. Mol Psychiatry 2008;13:27-35.

12 Zhang W, Bymaster FP: The in vivo effects of olanzapine and other antipsychotic agents on receptor occupancy and antagonism of dopamine D1, D2, D3, 5HT2A and muscarinic receptors. Psychopharmacology 1999;141:267-78.

13 Mencher S, Wang L: Promiscuous drugs compared to selective drugs (promiscuity can be a virtue). BMC Clin Pharmacol 2005;5:3.
14 Roth BL, Sheffler DJ, Kroeze WK: Magic shotguns versus magic bullets: selectively non-selective drugs for mood disorders and schizophrenia. Nat Rev Drug Discov 2004;3:353-9.

15 IPA: Ingenuity ${ }^{\circledR}$ Systems, IPA 5.5.1-1002, 2007. www.ingenuity.com.

16 Yildirim MA, Goh KI, Cusick ME, Barabasi AL, Vidal M: Drug-target network. Nat Biotechnol 2007;25:1119-26.

17 Calvano S, Xiao W, Richards DR, Felciano RM, Baker HV, Cho RJ, Chen RO, Brownstein BH, Cobb JP, Tschoeke SK, Miller-Graziano C, Moldawer LL, Mindrinos MN, Davis RW, Tompkins RG, Lowry SF; Inflamm and Host Response to Injury Large Scale Collab. Res. Program: A network-based analysis of systemic inflammation in humans. Nature 2005;437:1032-7.

18 Paolini GV, Shapland RH, van Hoorn WP, Mason JS, Hopkins AL: Global mapping of pharmacological space. Nat Biotechnol 2006;24:805-15.

19 Myslobodsky M: Molecular network of obesity: What does it promise for pharmacotherapy? Obes Rev 2007;: DOI: 10.1111/j.1467-789X.2007,00424.x.

20 Elman I, Borsook, D, Lukas, SE: Food intake and reward mechanisms in patients with schizophrenia: implications for metabolic disturbances and treatment with second-generation antipsychotic agents. Neuropsychopharmacology 2006;31:2091-120.

21 Arulmozhi DK, Dwyer DS, Bodhankar SL: Antipsychotic induced metabolic abnormalities: an interaction study with various PPAR modulators in mice. Life Sci 2006;79:1865-72.

22 Theisen FM, Haberhausen M, Firnges MA, Gregory P, Reinders JH, Remschmidt H, Hebebrand J, Antel J: No evidence for binding of clozapine, olanzapine and/or haloperidol to selected receptors involved in body weight regulation. Pharmacogenomics J 2007;7:275-81.

23 Liu J, Zhao J, Di YF, Guo XX, Zhai GR, Huang $\mathrm{XH}$ : The dynamic changes of plasma neuropeptide $\mathrm{Y}$ and neurotensin and their role in regulating cerebral hemodynamics in neonatal hypoxic-ischemic encephalopathy. Am J Perinatol 2007;7:435-40.

24 Nishi H, Nishi KH, Johnson AC: Early growth response-1 gene mediates up-regulation of epidermal growth factor receptor expression during hypoxia. Cancer Res 2002;62:827-34

25 Sun Y, Goderie SK, Temple S: Asymmetric distribution of EGFR receptor during mitosis generates diverse CNS progenitor cells. Neuron 2005;45:873-86.

26 de Jongh RT, Ijzerman RG, Serne EH, et al: Visceral and truncal subcutaneous adipose tissue are associated with impaired capillary recruitment in healthy individuals. J Clin Endocrinol Metab 2006; 91:5100-6.
27 Kitlinska J, Lee EW, Movafagh S, Pons J, Zukowska $\mathrm{Z}$ : Neuropeptide Y-induced angiogenesis in aging. Peptides 2002;23:71-7.

28 Ribatti D, Conconi MT, Nussdorfer GG. Nonclassic endogenous novel regulators of angiogenesis. Pharmacol Rev 2007;59:185-205.

29 Bates DO, Hillman NJ, Williams B, Neal CR, Pocock TM: Regulation of microvascular permeability by vascular endothelial growth factors. J Anat 2002;200:581-97.

30 Lohela M, Saaristo A, Veikkola T, Alitalo K: Lymphangiogenic growth factors, receptors and therapies. Thromb Haemost 2003;90:167-84.

31 Cao Y: Angiogenesis modulates adipogenesis and obesity. J Clin Invest 2007;117:2362-8.

32 Lijnen HR: Angiogenesis and obesity. Cardiovasc Res 2007: DOI: $10.1093 / \mathrm{cvr} / \mathrm{cvm} 007$.

33 Uvnäs-Moberg K, Alster P, Svensson TH: Amperozide and clozapine but not haloperidol or raclopride increase the secretion of oxytocin in rats. Psychopharmacology (Berl) 1992;109:473-6.

34 Ma FX, Han ZC: Akt signaling and its role in postnatal neovascularization. Histol Histopathol 2005; 20:275-81.

35 Cattaneo MG, Chini B, Vicentini LM: Oxytocin stimulates migration and invasion in human endothelial cells. Br J Pharmacol 2007: DOI: $\underline{10.1038 /}$ si.bjp.0707609.

36 Melkersson KI, Dahl ML: Relationship between levels of insulin or triglycerides and serum concentrations of the atypical antipsychotics clozapine and olanzapine in patients on treatment with therapeutic doses. Psychopharmacology (Berl) 2003;170: 157-66.

37 Hosojima H, Togo T, Odawara T, et al: Early effects of olanzapine on serum levels of ghrelin, adiponectin and leptin in patients with schizophrenia. J Psychopharmacol 2006;20:75-9.

38 Sporn AL, Bobb AJ, Gogtay N, Stevens H, Greenstein DK, Clasen LS, Tossell JW, Nugent T, Gochman PA, Sharp WS, Mattai A, Lenane MC, Yanovski JA, Rapoport JL: Hormonal correlates of clozapine-induced weight gain in psychotic children: an exploratory study. J Am Acad Child Adolesc Psychiatry 2005;44:925-33.

39 Hägg S, Söderberg S, Ahrén B, Olsson T, Mjörndal $\mathrm{T}$ : Leptin concentrations are increased in subjects treated with clozapine or conventional antipsychotics. J Clin Psychiatry 2001;62:843-8.

40 Melkersson K, Hulting AL: Antipsychotic drugs can affect hormone balance. Weight gain, blood lipid disturbances and diabetes are important (in Swedish). Lakartidningen 2001;98:5462-4, 5467-9. 
41 Thurston G, Rudge JS, Ioffe E, Zhou H, Ross L, Croll SD, Glazer N, Holash J, McDonald DM, Yancopoulos GD: Angiopoietin-1 protects the adult vasculature against plasma leakage. Nat Med 2002; 6:460-3.

42 Singh LK, Boucher W, Pang X, et al: Potent mast cell degranulation and vascular permeability triggered by urocortin through activation of corticotropin-releasing hormone receptors. J Pharmacol Exp Ther 1999;288:1349-56.

$\checkmark 43$ Allison DB, Fontaine KR, Heo M, Mentore JL, Cappelleri JC, Chandler LP, Weiden PJ, Cheskin LJ: The distribution of body mass index among individuals with and without schizophrenia. J Clin Psychiatry 1999;60:215-20.

44 Baptista T: Body weight gain induced by antipsychotic drugs: mechanisms and management. Acta Psychiatr Scand 1999;100:3-16.

45 Hanson D, Gottesman I: Theories of schizophrenia: a genetic-inflammatory-vascular synthesis. BMC Medical Genetics 2005;6:7.

46 Curtis CE, Iacono WG, Beiser M: Relationships between nailfold plexus visibility and clinical, neuropsychological, and brain structural measures in schizophrenia. Biol Psychiatry 1999;46:102-9

47 Akkaya C, Sarandol A, Aydogan K, Kirli S: Urticaria and angio-oedema due to ziprasidone. J Psychopharmacol 2007;21:550-2.

48 Gelly F, Chambon O, Marie-Cardine M: Long-term clinical experience with clozapine (in French). Encephale 1997;23:385-96.

$49 \mathrm{Ng} \mathrm{B}$, Postlethwaite A, Rollnik J: Peripheral oedema in patients taking olanzapine. Int Clin Psychopharmacol 2003;18:2003.

50 Mishra B, Sahoo S, Sarkar S, Akhtar S: Clozapineinduced angioneurotic edema. Gen Hosp Psychiatry 2007;29:78-80.

51 Haustein UF, Seikowski K: Psychosomatic dermatology (in German). Dermatol Monatsschr 1990; 176:725-33.

52 Harvey NL, Srinivasan RS, Dillard ME, et al: Lymphatic vascular defects promoted by Prox1 haploinsufficiency cause adult-onset obesity. Nat Genet 2005;37:1072-81.

53 Avram MM, Avram AS, James WD: Subcutaneous fat in normal and diseased states: 3 . Adipogenesis: from stem cell to fat cell. J Am Acad Dermatol 2007:56:472-92.

54 Kim SF, Huang AS, Snowman AM, Teuscher C, Snyder SH: From the cover: antipsychotic drug-induced weight gain mediated by histamine $\mathrm{H} 1 \mathrm{re}$ ceptor-linked activation of hypothalamic AMP-kinase. Proc Natl Acad Sci U S A 2007;104:3456-9.

55 Ouchi N, Shibata R, Walsh K: AMP-activated protein kinase signaling stimulates VEGF expression and angiogenesis in skeletal muscle. Circ Res 2005; 96:838-46.
56 Treins C, Murdaca J, Van Obberghen E, GiorgettiPeraldi S: AMPK activation inhibits the expression of HIF-1[alpha] induced by insulin and IGF-1. Biochem Biophys Res Commun 2006;342:1197- 202.

57 Goirand F, Solar M, Athea Y, et al: Activation of AMP kinase alpha1 subunit induces aortic vasorelaxation in mice. J Physiol 2007:581:1163-71.

58 Minokoshi Y, Kim YB, Peroni OD, Fryer LG, Müller C, Carling D, Kahn BB: Leptin stimulates fatty-acid oxidation by activating AMP-activated protein kinase. Nature 2002;415:339-43.

59 Dimmeler S, Zeiher AM: Endothelial cell apoptosis in angiogenesis and vessel regression. Circ Res 2000;87:434-9.

60 Hausman GJ, Richardson RL: Adipose tissue angiogenesis. J Anim Sci 2004;82:925-34.

61 Potente M, Ghaeni L, Baldessari D, et al: SIRT1 controls endothelial angiogenic functions during vascular growth. Genes Dev 2007;21:2644-58.

62 Chavakis E, Dimmeler S: Regulation of endothelial cell survival and apoptosis during angiogenesis. Arterioscler Thromb Vasc Biol 2002;22:887-93.

63 Weinberger DR: From neuropathology to neurodevelopment. Lancet 1995;346:552-7.

64 Seo S, Fujita H, Nakano A, Kang M, Duarte A, Kume T: The forkhead transcription factors, Foxc1 and Foxc2, are required for arterial specification and lymphatic sprouting during vascular development. Dev Biol 2006;294:458-70.

65 Barker DJP: Mothers, Babies and Disease in Later Life. London, BMJ Publishing, 1994.

66 McMillen I, Robinson J: Developmental origins of the metabolic syndrome: prediction, plasticity, and programming. Physiol Rev 2005;85:571-633.

67 Igosheva N, Taylor PD, Poston L, Glover V: Prenatal stress in the rat results in increased blood pressure responsiveness to stress and enhanced arterial reactivity to neuropeptide $\mathrm{Y}$ in adulthood. J Physiol 2007;582:665-74.

68. Gao Y-J, Holloway AC, Zeng Z-h, et al: Prenatal exposure to nicotine causes postnatal obesity and altered perivascular adipose tissue function. Obesity Res 2005;13:687-92.

69 Futamura T, Kakita A, Tohmi M, Sotoyama H, Takahashi H, Nawa H: Neonatal perturbation of neurotrophic signaling results in abnormal sensorimotor gating and social interaction in adults: implication for epidermal growth factor in cognitive development. Mol Psychiatry 2003;8:19-29.

70 Nishimura S, Manabe I, Nagasaki M, et al: Adipogenesis in obesity requires close interplay between differentiating adipocytes, stromal cells, and blood vessels. Diabetes 2007;56:1517-26.

71 van Harmelen V, Dicker A, Ryden M, et al: Increased lipolysis and decreased leptin production by human omental as compared with subcutaneous preadipocytes. Diabetes 2002;51:2029-36.
72 Hemmrich K, Gummersbach C, Pallua N, Luckhaus C, Fehsel K: Clozapine enhances differentiation of adipocyte progenitor cells. Mol Psychiatry 2006;11: 980-1.

73 Okuno A, Tamemoto H, Tobe K, et al: Troglitazone increases the number of small adipocytes without the change of white adipose tissue mass in obese Zucker rats. J Clin Invest 1998;101:1354-61.

74 Gavrilova O, Marcus-Samuels B, Graham D, et al: Surgical implantation of adipose tissue reverses diabetes in lipoatrophic mice. J Clin Invest 2000;105: 271-8.

75 Frayn KN: Adipose tissue as a buffer for daily lipid flux. Diabetologia 2002;45:1201-10.

76 Karnieli E, Barzilai A, Rafaeloff R, Armoni M: Distribution of glucose transporters in membrane fractions isolated from human adipose cells. Relation to cell size. J Clin Invest 1986;78:1051-5.

77 Skurk T, Alberti-Huber C, Herder C, Hauner H: Relationship between adipocyte size and adipokine expression and secretion. J Clin Endocrinol Metab 2007;92:1023-33.

78 Danforth EJ: Failure of adipocyte differentiation causes type II diabetes mellitus? Nat Genet 2000; 26:13.

79 Thakore JH, Mann JN, Vlahos I, Martin A, Reznek $\mathrm{R}$ : Increased visceral fat distribution in drug-naive and drug-free patients with schizophrenia. Int $\mathrm{J}$ Obes Relat Metab Disord 2002;26:137-41.

80 Yang R-Z, Lee M-J, Hu H, et al: Identification of omentin as a novel depot-specific adipokine in human adipose tissue: possible role in modulating insulin action. Am J Physiol Endocrinol Metab 2006;290:E1253-61.

81 Feinman R, Fine E: 'A calorie is a calorie' violates the second law of thermodynamics. Nutrit J 2004; 3:9.

82 Astrup A, Greenway FL, Ling W, Pedicone L, Lachowicz J, Strader CD, Kwan, R; for the Ecopipam Obesity Study Group: Randomized controlled trials of the D1/D5 antagonist ecopipam for weight loss in obese subjects Obesity 2007;15:1717-31.

83 Mourad JJ, des Guetz G, Debbabi H, Levy BI: Blood pressure rise following angiogenesis inhibition by bevacizumab. A crucial role for microcirculation. Ann Oncol 2007: DOI 10.1093/annonc/mdm 550.

84 Savla U, Neal CR, Michel CC: Openings in frog microvascular endothelium at different rates of increase in pressure and at different temperatures. $\mathrm{J}$ Physiol 2002;539:285-93.

85 Henderson DC, Daley TB, Kunkel L, RodriguesScott M, Koul P, Hayden D: Clozapine and hypertension: a chart review of 82 patients. J Clin Psychiatry 2004;65:686-9. 